\title{
Mixing Urea and Zeolite for Slow Release Fertilizer using Orbiting Screw Mixer
}

\author{
Semuel Pati Senda ${ }^{1}$, Renanto Handogo ${ }^{1}$, Achmad Roesyadi ${ }^{1}$, and Wahono Sumaryono ${ }^{1}$
}

\begin{abstract}
Slow release fertilizer (SRF) of urea is prepared by using zeolite as the matrix. Mixing of urea and zeolite is carried out in orbiting screw mixer. The effects of rotation speed and orbital speed of the mixer and particle size on power consumption, homogeneity, mixing time and specific energy consumption are evaluated. The experimental results show that higher orbital speed gives higher power consumption. Power consumption is dominated by mixer rotation motion. Smaller particle size needs higher power for mixing process. Nitrogen mass fraction ranges from 0.45 to 0.49 when mixture reaches homogeneity. The mixing time required is about $5-12$ minutes for particle size of $>60$ and $>80$ mesh and $7-14$ minutes for particle size of $>\mathbf{5 0}$ mesh. At constant orbit speed, the higher the screw rotation speed, the shorter time needed to reach mixture homogeneity. Specific energy consumption of mixing process increases with decreasing particle size. For the three particle size groups of $>80$ mesh, $>60$ mesh and $>50$ mesh, the lowest specific energy consumption is given by combination of orbital speed of 5 rpm and rotation speed of $50 \mathrm{rpm}$; while for particle size of $>60$ mesh and $>80$ mesh, it can obtained by combination of orbital speed of $5 \mathrm{rpm}$ and rotation speed of $67,5 \mathrm{rpm}$ and orbital speed $5 \mathrm{rpm}$ and rotation speed $30 \mathrm{rpm}$, respectively. The lowest specific energy consumptions is gained by combination of orbital and rotation speeds of 5 and $50 \mathrm{rpm}$ with particle size of $>50$ mesh.
\end{abstract}

Keywords-Homogeneity, mixing time, orbiting screw mixer, solid-solid mixing, specific energy consumption.

\section{INTRODUCTION}

$\mathrm{S}$ olid-solid mixing is widely applied in many industries such as pharmaceutical, foodstuffs, petrochemical, plastics, ceramic, and fertilizers. The objective of this process is to produce homogeneous mixture with a minimum energy consumption and time $[1,2]$. Mixing process is a complex phenomenon which involves (a) convection, where groups of particles moved from one location to the other within the bulk; (2) diffusion, where individual particles moved with respects to its neighbors; and (c) shearing, where groups of particles are mixed through the formation of slipping planes [2].

There are many variables can influence mixing mechanism, and thus influence mixture homogeneity: (a) characteristics of solids, including particle size, particle shape and surface characteristics, bulk density and particle density, moisture content, angle of repose, friability, state of agglomeration and flowability; (b) characteristics of mixing equipment, including mixer dimension and geometry, agitator dimension,

${ }^{1}$ All Authors are with Department of Chemical Engineering, Faculty of Industrial Technology, Faculty of Industrial Technology, Institut Teknologi Sepuluh Nopember, Surabaya, 60111, Indonesia. E-mail: sps_24@yahoo.co.id. construction materials and surface finishes, type, location, and number of loading; (c) operating conditions, including weight of each materials added, ratio of volume of the mixer to that of the mixer, and mixer or agitation speed [3].

In this work, urea mixes with natural zeolite to form slow release fertilizer (SRF) for increasing urea nutrient use efficiency and minimizing its negative impacts on environment. Several types of SRF zeolite-based have been developed. Eberl [4] prepared SRF urea by using molten urea and heated zeolite rock chips as the matrix while Chang [5] used liquefied urea. Notario del Pino et al. [6] prepared $\mathrm{P}$ and $\mathrm{K}$ SRFs from concentrated solutions of $\mathrm{KH}_{2} \mathrm{PO}_{4}$ and $\mathrm{K}_{2} \mathrm{HPO}_{4}$. Bansiwal et al. [7] used surfactant-modified zeolite for SRF of phosphorus. However, none of these works performed solid-solid mixing process.

Considering the hygroscopic characteristic of urea that leads to the tendency of being sticky when exposed to moist atmosphere, orbiting screw mixer is chosen as the mixing device. This mixer is commonly used in pharmacy industry. In addition to the hygroscopic properties, orbiting screw mixer is suitable for the process that needs force mixing and has low energy consumption, shorter mixing time, and range capacity from 50 to 25.000 liter [8].

In order to gain optimum mixing process, an understanding of mixing characteristics and behavior becomes essential. Unfortunately, only few studies about solid-solid mixing processes characteristics have been reported. Bauman et al. studied the effects of particle size and cohesion index of quartz sand mixing process in V-blender, Turbula, and static mixer [1]. Portillo et al. studied the effect of vessel loading on mixing and sampling methods on the accuracy of mixture homogeneity in V-blender [9]. Porion et al. investigated dynamics of mixing and segregation process of grain using NMR Imaging in Turbula [10]. Mohaker et al. studied mixing of non-cohesive grain and simulated segregation phenomena in double cone and V-blender [11]. None of this works used orbiting screw mixer as the mixing device. Schweiger et al. mixed lactose and corn starch in planetary mixer [12]. However, this work only emphasized to mixing time requirement. Hence, there is a need for study of mixing performance characteristics such as mixture homogeneity, mixing time, and power requirement which are affected by particle size and mixing operation in orbiting screw mixer.

The objective of this works is to evaluate the effects of orbital and rotation speed of the mixer and particle size on mixture homogeneity, mixing time, power consumption, and specific energy consumption. 


\section{FUNDAMENTAL THEORY}

In solid-solid mixing, mixing occurs due to the diffusion, convection, and shear. All these three mechanisms may exist in one single mixer, but one or two may predominate [13]. For orbiting screw mixer, the screw rotation and orbital motions causes the mixture to lift and spread on a surface. The mixing is predominantly caused by combination of both shear and convection in which particles move randomly from one point to the other, along with the bulk mass [8].

There are many aspects that affect the mixing process. Particles size is an important in determining the flow characteristic. When the powder particles are freely distributed within the bulk, there will be formation of either free flowing or non-free flowing (cohesive) mixtures depending on the particle size [14]. Smaller particles have a tendency to agglomerate because the gravitational separation forces between particles become less and inter-particulate bonding forces such as Van der Waals or moisture bonding forces become more significant. Particle of larger diameter tend to be free flowing. The same particle sizes will avoid segregation. Segregation is preferential movement of particles to the certain regions of the mixer due to the differences in particulate properties. Segregation mainly caused by difference in particle size, shape, density, and resilience. Size difference is the most important cause that leads to a serious segregation problems [3].

Density difference in the components that will be mixed may cause increasing mixing time and segregation. The denser material will sink through the lighter one, leaving the less dense particles on the top [15]. If denser particles at the start mixing are in the lower part, the degree of mixing will increase gradually until equilibrium is attained. If they are in the upper layer, the denser component falls through the lighter one that leads to segregation.

Moist and sticky particles retard the mixing process if they adhere to the walls of the mixer or if they cause agglomeration [16]. Interactions between solid particles and the construction materials of a mixer may cause agglomeration. Friction between particles and the surface of a mixer gives some effect on mixing and de-mixing (segregation).

Ratio of the components in the mixture is also important in causing segregation and agglomeration. Ratio of 1:1 gives higher homogeneity. Mixing time must be adequate to obtain homogeneity. Extended mixing time may lead to the segregation and poor mixture quality [17]. Other performance characteristic that also has to be considered in mixing process is the power requirement. Sufficient power must be provided during mixing process [18].

Ideally, the mixture obtains perfect homogeneity where the particles have the same composition. However, real mixture suffers from heterogeneity due to the incomplete mixing, agglomeration, and segregation. Based on homogeneity characteristic, mixtures may be divided into prefect mixture, random mixture, and ordered mixture [17]. In reality, perfect mixture which has identical particles is never achieved. Random mixture follows statistical or probabilistic process. Generally, mixture quality is measured based on statistical methods such as Relative Standard Deviation (RSD). Perfect mixture has zero variance; while ordered mixture can have less variance than that of random mixture. A high quality mixture will have very little variation in composition between samples, thus low standard deviation.

\section{METHODS}

\section{A. Materials}

Natural zeolite used as SRF matrix is second grade zeolite from Malang. Urea is industrial grade from PT. Pupuk Kaltim. Both urea and zeolite are crushed into the size range from 50-80 mesh and then sieved to obtain three size groups of $>50,>60$ and $>80$ mesh before mixing. The bulk densities of urea and zeolite are given by $1.19 \mathrm{~g} / \mathrm{cm}^{3}$ and $0.57 \mathrm{~g} / \mathrm{cm}^{3}$, respectively.

\section{B. Equipment}

Orbiting screw mixer used in this work is adapted from the mixer which usually used as the powder mixer in the pharmaceutical industry. The size of this mixer is scaled-down to 1:10 with the effective height of $6 \mathrm{~m}$ (Fig. 1). The mixer's wall is made from flexi glass. The conical diameter at the top and the bottom of the mixer are $500 \mathrm{~mm}$ and $100 \mathrm{~mm}$, respectively. The angle of the screw conveyor from the vertical axis is about $18^{\circ}$. The mixer uses three-phase motor as the driver with the speed of $1500 \mathrm{rpm}$. The mixer is equipped with gear reducer and speed controller.

\section{Mixing Process}

In order to minimize the occurrence of segregation, mixtures weighing $16 \mathrm{~kg}$ with ratio of urea and zeolite $1: 1$ with the same particle sizes are mixed in the mixer. The orbital and rotation speeds should be sufficient to ensure homogeneity. From visual observation, position of the zeolite at the lower part give better mixing than that of at the upper part. Orbital speeds of 5, 10, and 15 $\mathrm{rpm}$ and rotation speeds of 30,50 , and $67.5 \mathrm{rpm}$ give effective materials movements within the bulk mass. Therefore, these speeds are selected for further tests. Based on the previous experiments for batch mixing, mixings are conducting for 15 minutes [18]. Throughout mixing experiments are duplicated.

\section{Data Acquisition Method}

Data acquisition in this system is carried out by using instrumentation device and data acquisition program. The data is obtained as the torque which transferred to the computer program by using radio frequency.

Fig. 2 depicts the design layout of equipment mixing experiment for data acquisition. This system has the capability of recording data with the time interval in seconds. Collecting data on the test system was done in real time with instruments and data acquisition program. The data recorded is the torque load on the stirring and rotation or screw axis of the orbit. Sensors used to measure the strain-gage torque. Load measurements made during the mixing process took place, so to send data to a computer to use radio frequencies. Velocity measurements performed using a proximity sensor. Data were processed first with a micro 
controller that can be processed in the course of data acquisition.

\section{E. Sampling}

Samples are taken manually from a certain point at the top of mixtures for every 24 second during mixing process. After mixing processes stop, samples are also taken from different heights of conical chamber.

\section{F. Power Comsuption Calculation}

To calculate the amount of power needed mixing process, can be calculated as follows:

Specific energy, $E=\left(\eta \times W_{\mathrm{m}} \times \mathrm{t}_{\mathrm{mx}}\right) / \mathrm{m},\left[\right.$ Joule. $\mathrm{kg}^{-1}$ ]

Mechanical power, $W_{\mathrm{m}}=\mathrm{T}_{\mathrm{m}} \mathrm{x} \omega$ [Watt]

Angular velocity, $\omega$ [rad.det ${ }^{-1}$ ]

Electrical power, $W_{1}=\mathrm{V} \times \mathrm{I}$ [Watt]

Torque, $\tau_{\mathrm{m}}=\mathrm{F}$ x $d[\mathrm{Nm}]$

where,

Force, $\mathrm{F}[\mathrm{N}]$

Orbital radius, $\mathrm{L}[\mathrm{m}]$

Mixing time, $\mathrm{t}_{\text {mix }}$ [second]

Mass, $\mathrm{m}$ [ kg]

Distance screw with the conus wall, $d[\mathrm{~cm}]$

\section{G. Sample Analysis}

In order to assess the homogeneity of mixture, the urea content is measured by gravimetric method. Sample is weighted around $0.6-0.7$ grams. Distillated water is added about $11-12 \mathrm{~mL}$ and then sample is agitated for 2 minutes. Then, sample is centrifuged around 15 minutes with the speed of centrifuge of $3000 \mathrm{rpm}$. After centrifuging, sample is dried in the oven with the temperature of $110^{\circ} \mathrm{C}$ until sample weight is constant $( \pm$ 17 hours).

\section{EXPERIMENTAL RESULTS}

In this study, orbital and rotation speeds of screw are varied together with the particle sizes of components that are mixed. The following section examine the effects of these parameters in mixing performance if the mixer.

\section{A. The Effects of Particle Size and Mixer Speeds on Mixture Homogeneity and Mixing Time}

Fig. $3-5$ depicts profiles of mixture homogeneity during mixing processes for particle sizes of $>50$ mesh, $>60$ mesh and >80 mesh, respectively. From these figures, it can be shown that at the beginning of mixing, the concentration of urea is still high due to the short time interval of mixing. After several cycles, the urea fraction reduces to its ideal value of homogeneity of 0.5 . This indicates that the mixing time is enough to permit the particles of components to move between their neighbor particles. However, when mixing time is lengthened, the urea fraction becomes lower than its ideal homogeneity value. The extended mixing time leads to the segregation of the mixture [17].

Fig. 3 depicts the homogeneity of particle size of $>50$ mesh mixing processes. The tendencies are similar with those of particle size of $>60$ mesh and $>80$ mesh. However, the mixing time to obtain homogeneity for particle size of $>50$ mesh is longer than that of $>60$ mesh. The mixing time needed to obtain homogeneity ranges from 7 to 14 minutes. Increasing particle size decreases surface area that result in lower particle interaction between two components. Therefore, the longer mixing time need to achieve homogeneity.

From Fig. 4, it can be shown that for the mixing of particle size of 60 mesh, the mass fraction of nitrogen in the mix is still high at the beginning of the process of mixing. Then fraction decreases until it becomes relatively stable and reaches the target value of about 0.5 . This indicates that the homogeneity of the mixture in the tube cone has been achieved. The mass fractions of urea when the mixtures obtain homogeneities range from 0.45 up to 0.49 . Mixing time to obtain homogeneity ranges from 5 to 12 minutes.

Fig. 5 shows the mixing of particle size of $>80$ mesh. The experimental results show that the mixing times required to produce homogeneous mixture are ranged from 5 to 12 minutes. These values are similar with those of particle size> 60 mesh.

There were different time optimum mixing time have been reported [12]. According to the Poux, ideal mixing time for planetary mixers is about 2 to 10 minutes. Sucker et al. and Schweiger et al. observed that mixing time ranges from 10 to 20 minutes or even up to $1 \mathrm{~h}$. However, in this study, the values lie between these two ranges. At constant orbital speed, the higher the screw rotation speed, the shorter time needed to achieve homogeneity. On the other hand, at constant rotation speed, the higher orbital speed also gives shorter mixing time. This indicates that in orbiting screw mixer, convective and shear mixings dominate mixing mechanism [8]. At higher speed, the components mixed undergo greater shear forces that promote mixing in the axial and radial direction. Portillo et al. also observed the same phenomena for mixing in blender device which mixing mechanism is dominated by convective mixing [9].

At rotation speed of $67.5 \mathrm{rpm}$, the urea fractions obtained are lower than other speeds. It can be explained that the higher the speed of screw rotation, the more material movement thrown to the sideward due to the greater shear force by the screw. This movement promote to de-mixing the mixture that result in lower fraction of urea.

\section{B. The Effects of Particle Size and Mixer Speeds on Power Consumption}

Fig. 6, 8 and 10 depict the effects of orbital and rotation speeds on power consumptions for particle size of >50 mesh, >60 mesh and >80 mesh. From these figures, it can be shown that power consumptions for particle size $>60$ mesh tend to decrease, except for orbital speed $10 \mathrm{rpm}$. At this speed, power consumptions tend to increase with the increasing of rotation speed. For the particle size of $>80$ mesh, power consumptions also tend to increase, except for the orbital speed of $15 \mathrm{rpm}$. At constant orbital speed, the higher rotation speed, the higher power consumption. Likewise, higher rotation speed gives higher power consumption.

These figures also shows that the higher rotation speeds, the higher power consumptions needed for the orbital speed of $5 \mathrm{rpm}$. On the other hand, for the orbital speed of $10 \mathrm{rpm}$, power consumptions tend increase with the increasing of rotation speed to $67.5 \mathrm{rpm}$. It can be explained that at orbital speed of $5 \mathrm{rpm}$, material moved 
by orbital force is relatively fewer than that of lifted by screw rotation motion. Thus, the screw rotation dominates materials movements. If the orbital speed increases up to $15 \mathrm{rpm}$, the orbital force is high enough to overcome friction so that materials can be spread more freely in tangential direction.

At constant orbital speed, the higher screw rotation speed, the higher mixture aggregates decrease in size that leads to the lower friction against the material motion. Thus, the lower force requires for mixing process. On the other hand, higher orbital speed requires higher power consumption for all rotation speed variations. The lowest power consumption is gained by combination of orbital and rotation speeds of 5 and $67.5 \mathrm{rpm}$, respectively.

Compared to the particle size of $>60$ mesh and $>80$ mesh mixing process, power consumptions for particle size of $>50$ mesh are lower for all variation of screw rotation and orbital speeds. Particle size has influence on particle flowability. Fine particles with high surface to volume ratios are more cohesive than course particles. Fine particles can stick to one another in relatively rigid aggregate [17]. Therefore, the force needed to move the particles are higher due to the breaking down this aggregate. Thus, the power consumption for mixing particles of 80 mesh is higher than that of $>50$ mesh and $>60$ mesh.

Based on mechanical requirements of the orbiting screw mixer established for the operating performance, it can be shown that the higher the ratio of orbital velocity and rotation speed showed increased power consumption for all particle size variations.

The effect of orbital and rotation speeds on rotation power fraction are shown in Fig. 7, 9 and 11 for the particle size of $>50$ mesh, $>60$ mesh, and >80 mesh, respectively. The rotation power consumption fractions are higher than 0.5 . These values indicate that power consumptions are dominated by screw rotation motion. The higher the rotation speed, the higher the rotation power consumption fraction at constant orbital speed. On the contrary, higher orbital speed gives lower rotation power fraction at constant rotation speed. It can be explained that higher orbital speed gives more power to overcome friction and break up agglomerate that result in reducing power need for axially movement by rotation motion.

The tendencies are similar to both of particles size $>50$ mesh and >60 mesh. The higher rotation speed, the higher rotation power fraction needed. On the other hand, the higher orbital speed, the lower power consumption by rotation motion. Thus, the lower rotation power fraction from total power consumption required.

\section{Specific Energy Consumption}

Energy consumption required for mixing process is one of important factors which affect the cost. Therefore, energy consumption is expected as low as possible. Table 2 shows specific energy consumption needed for urea-zeolite mixing. From this table, it can be shown that specific energy consumptions for particle size of $>60$ and $>80$ mesh are higher than those of $>50$ mesh. Specific energy consumption increases with rotation speed. As mentioned before, the fine particles is more cohesive than the coarse one that leads to the higher force needs to break down the aggregate formed during mixing process. On the other hand, mixing time for fine particle is shorter than that of coarse particle. Therefore, there is a tradeoffs between the power consumption and mixing time. The optimum energy specific consumption achieves by considering these two parameters.

For the three particle size $>50$ mesh, the lowest specific energy consumption is given by combination of orbital speed of $5 \mathrm{rpm}$ and rotation speed of $50 \mathrm{rpm}$; while for particle size of $>60$ mesh and $>80$ mesh, the lowest values obtained by the combinations of orbital speed of $5 \mathrm{rpm}$ and rotation speed of 67,5 rpm and orbital speed $5 \mathrm{rpm}$ and rotation speed $30 \mathrm{rpm}$, respectively. From all variation, the lowest specific energy consumptions is gained by combination of orbital and rotation speeds of 5 and $50 \mathrm{rpm}$ with particle size of $>50$ mesh.

\section{Mixture Homogeneity Profile}

Profile urea-zeolite mixture homogeneities are shown in Fig. 12 - 14 for the particle size $>50$ mesh, $>60$ mesh and $>80$ mesh, respectively. From these figures, it can be shown that homogeneities obtain with mixture urea fractions ranging from 0.46 to 0.5 . In general, the concentration of urea in the mixer along the tube is relatively constant from the top of the mixture until the height of $17 \mathrm{~cm}$ for all variations of the rotation screw mixer. While at the lower part of the mixer conical chamber until it reaches the bottom of the mixer (cone base), the concentration of urea in the mixture is lower than it should. This shows that in this region, the mixing does not take place effectively. Urea concentration difference for particle size > 50 mesh particles are relatively large compared with size $>60$ and $>80$ mesh.

\section{SUMMARY}

Slow release fertilizer is prepared by mixing solid urea and natural zeolite in orbiting screw mixer. The effects of orbital speed, rotation speed, and particle size on mixture homogeneity, mixing time, power and specific energy consumption are evaluated. The experimental results show that higher orbital speed gives higher power consumption. The power consumptions in ascending order are particle size of 80 mesh > 60 mesh > 50 mesh. Power consumption is dominated by mixer rotation motion.

Mixture homogeneity ranges from 0.45 up to 0.49 of nitrogen mass fraction. The mixing time required ranges from 5 to 12 minutes for particle sizes of $>60$ mesh and $>80$ mesh; while for particle sizes of $>50$ mesh, mixing time range from 7 to 14 minutes. At constant orbital speed, the higher the screw rotation speed, the shorter time needed to reach mixture homogeneity. At constant rotation speed, the higher orbital speed also gives the shorter mixing time.

Specific energy consumption of mixing process increases with decreasing particle size. Combination orbital and rotation speeds of 5 and $50 \mathrm{rpm}$ gives lower specific energy consumption for particle size of $>50$ mesh, while for particle size of $>60$ mesh, it can be obtained by orbital speed of $5 \mathrm{rpm}$ and rotation speed of $67.5 \mathrm{rpm}$. For particle $>80$ mesh, lower energy 
consumption is given by the combination of speed of 5 and $30 \mathrm{rpm}$; The lowest energy consumption is gained by variation of orbital speed of $5 \mathrm{rpm}$, rotation speed of 50 rpm, and particle size of $>50$ mesh.

\section{REFERENCES}

[1] I. Bauman, D. Curic, and M. Boban, 2008, "Mixing of solids in different mixing devices", Shadana, vol. 33, part 6, pp. 721-731.

[2] J.A. Lindley, "Mixing processes for agricultural and food materials: 3. Powders and particulates", J. Ugric. Engng Res., vol. 49, pp. 1-19.

[3] W. Nienow, N. Harby, and M.E.W. Edwards, 1993, Mixing in the process industries, Second Edition, Butterworth-Heinemann.

[4] D. Eberl, "Controlled Release Fertilizers Using Zeolites", US Geological Survey.

[5] J. Chang, 1997, "Method of Preparing Slow Release Fertilizer", U.S Patent $005695542 A$, Dec. 9 .

[6] J.J. S. Notario, I. J. Arteaga, M. M. G. Martin, and J. E. G Herndndez, 1995, "Phosphorus and potassium release from phillipsite-based slow-release fertilizers", Journal of Controlled Release, vol. 34, pp. 25-29.

[7] K. Bansiwal, S. S. Rayalu, N. K. Labhasetwar, A. A. Juwarkar, and S. Devota, 2006, "Surfactan-modified zeolite as a slow release fertilizer for phosphorus", J. Agric. Food Chem. Vol. 54, pp. 4773-4779.

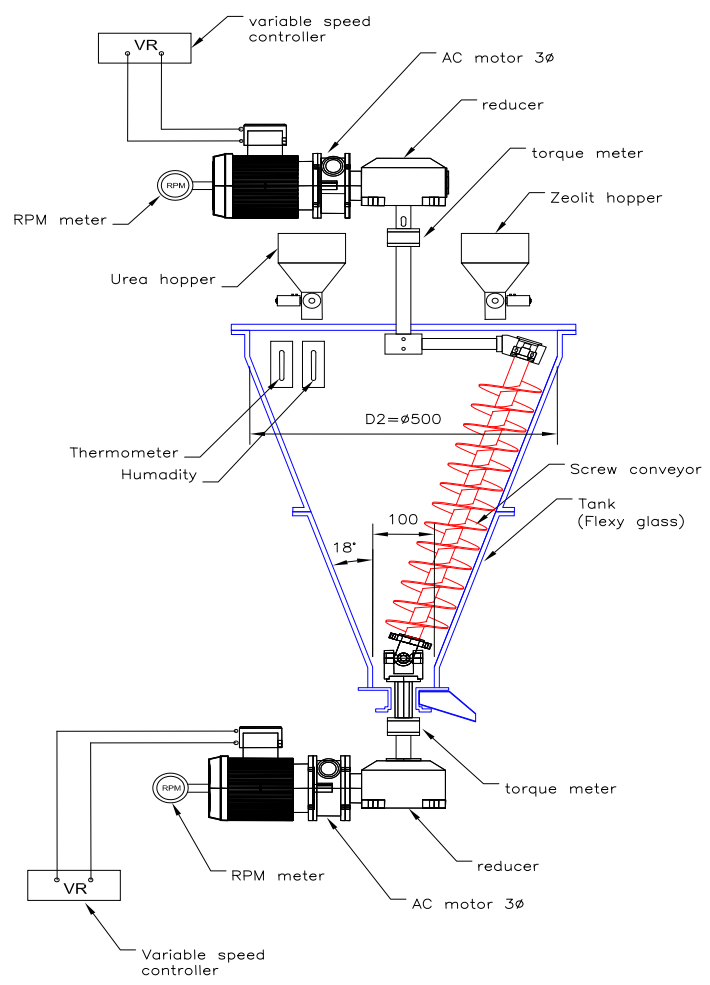

Fig. 1. Urea-zeolite mixer unit

TABLE 1

VARIATION OF SCREW ORBITAL AND ROTATION SPEED FOR MIXING PROCESS

\begin{tabular}{cccc}
\hline \multicolumn{2}{c}{ Orbital Screw } & \multicolumn{2}{c}{ Rotation Screw } \\
$\begin{array}{c}\text { Inverter } \\
(\mathrm{Hz})\end{array}$ & $\begin{array}{c}\text { Rpm } \\
\text { Orbit }\end{array}$ & $\begin{array}{c}\text { Inverter } \\
(\mathrm{Hz})\end{array}$ & $\begin{array}{c}\text { Rpm } \\
\text { Screw }\end{array}$ \\
\hline 8.5 & 5 & 20 & 30 \\
8.5 & 5 & 35 & 50 \\
8.5 & 5 & 45 & 67,5 \\
17 & 10 & 20 & 30 \\
17 & 10 & 35 & 50 \\
17 & 10 & 45 & 67,5 \\
24 & 15 & 20 & 30 \\
24 & 15 & 35 & 50 \\
24 & 15 & 45 & 67,5 \\
\hline
\end{tabular}

[8] Manjunath, S. Dhodapkar, and K. Jacob, 2004, "Mixing of Particulate Solids in the Process Industries", Handbook of Industrial Mixing: Science and Practice, (editor: Edward E Paul), the North American Mixing Forum and published by John Wiley \& Sons.

[9] P. M. Potillo, F. J. Muzzio, and M.G. Ierapetritou, 2006, "Characterizing powder mixing processes utilizing compartment models", International Journal of Pharmateutics., vol. 50(3), pp. 14-22.

[10] P. Porion, N. Sommiers, and P. Evesque, 2000, "Dynamics of mixing and segregation processes of grains in $3 \mathrm{~d}$ blender by NMR imaging investigation", Europhys Lett., vol. 50(3), pp. 319-325.

[11] M. Moakher, T. Shinbrot, and F.J. Muzzio, "Experimentally validated computations of flow, mxing and segregation of noncohesive grains in 3D tumbling blenders".

[12] Schweiger, U. Sindel, and I. Zimmerman, 1997, "Determination of optimum mixing time for a mixture of lactose and corn starch", Pharm. Ind., vol 59, pp. 985-988.

[13] R.G. Holdich, "Fundamentals of particle technology", Midland Information Technology and Publishing, pp. 123-130.

[14] R. Deverwaran et al., 2009, "Concept and techniques of pharmaceutical powder mixing process: A current update", Research J. Pharm. And Tech., vol 2(2), pp. 245-249.

[15] H. J. Venables and J. I. Wells, 2001, "Powder Mixing", Drug Developmet and industrial Pharmacy, vol. 27(7), pp. 599-612.

[16] T. Fan, S. J. Chen, and C. A. Watson, 1970, "Solid mixing", Industrial and Engineering Chemistry, vol. 62, pp. 53-69.

[17] F.J. Muzzio, A. Alexander, C. Goodridge, E. Shen, and T. Shinbrot, 2004, "Part A: Fundamental of solid mixing", Handbook of Industrial Mixing: Science and Practice, (editor: Edward E Paul)", the North American Mixing Forum and published by John Wiley \& Sons.

[18] Sastry et al., 1999, "Solid-solid operations and equipment", Perry's Chemical Engineer's Handbook (editor: R.H. Perry, D.W. Green), McGraw-Hill.

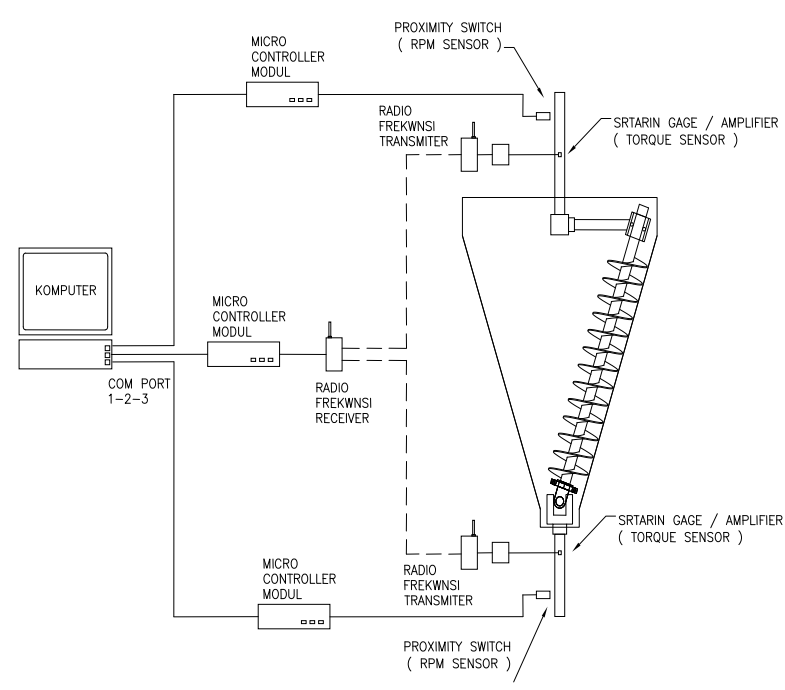

Fig.2.Set-up data acquisition system mixing process

TABLE 2.

SPECIFIC ENERGY CONSUMPTION

\begin{tabular}{crrrr}
\hline \multirow{2}{*}{$\begin{array}{c}\text { Orbital } \\
\text { speed }\end{array}$} & \multirow{2}{*}{$\begin{array}{c}\text { Rotation } \\
\text { speed } \\
(\mathrm{rpm})\end{array}$} & \multicolumn{3}{c}{ Specific energy consumption $(\mathrm{J} / \mathrm{kg})$} \\
\cline { 3 - 5 }$(\mathrm{rpm})$ & & $>80$ mesh & $>60$ mesh & $>50$ mesh \\
\hline 5 & 30 & 10,121 & 13673 & 13542 \\
5 & 50 & 15,660 & 11915 & 7931 \\
5 & 67.5 & 15,134 & 11291 & 11448 \\
10 & 30 & 16,986 & 16351 & 7959 \\
10 & 50 & 23,112 & 18140 & 10510 \\
10 & 67.5 & 28,553 & 19412 & 14076 \\
15 & 50 & 19,362 & 14918 & 10944 \\
15 & 67.5 & 24,840 & 13102 & 8806 \\
\hline
\end{tabular}




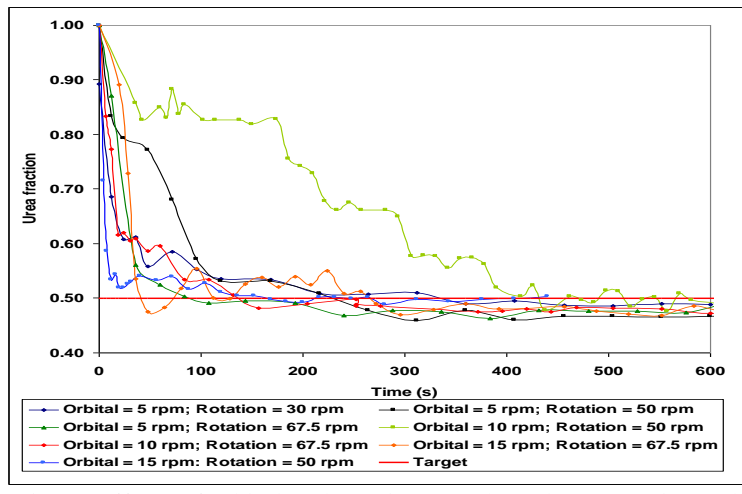

Fig. 3. Effects of orbital and rotation speeds on homogeneity and mixing time for particle size of $>50$ mesh



Fig. 4. Effects of orbital and rotation speeds on homogeneity and mixing time for particle size of $>60$ mesh

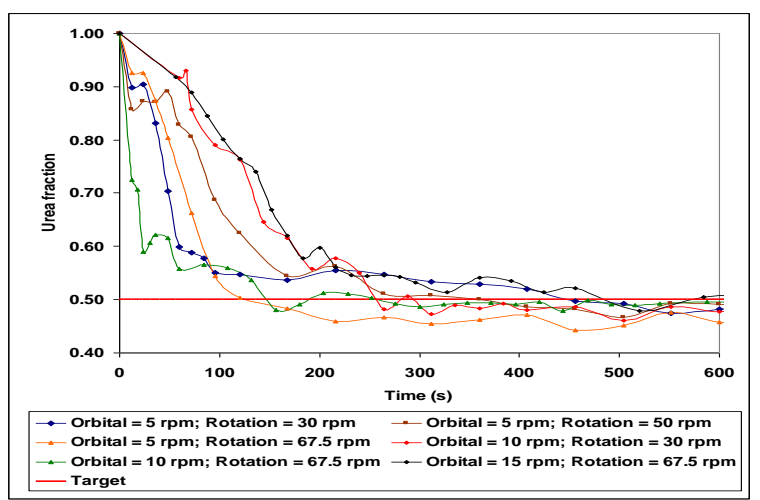

Fig. 5. Effects of orbital and rotation speeds on homogeneity and mixing time for particle size of $>80$ mesh

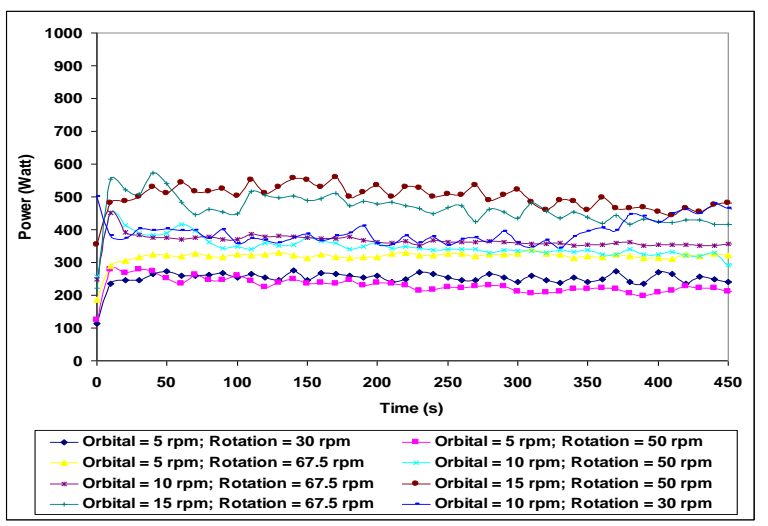

Fig.6. Effects of orbital and rotation speeds on power consumption for particle size of $>50$ mesh



Fig. 7. Rotation power fraction for particle size of $>50$ mesh

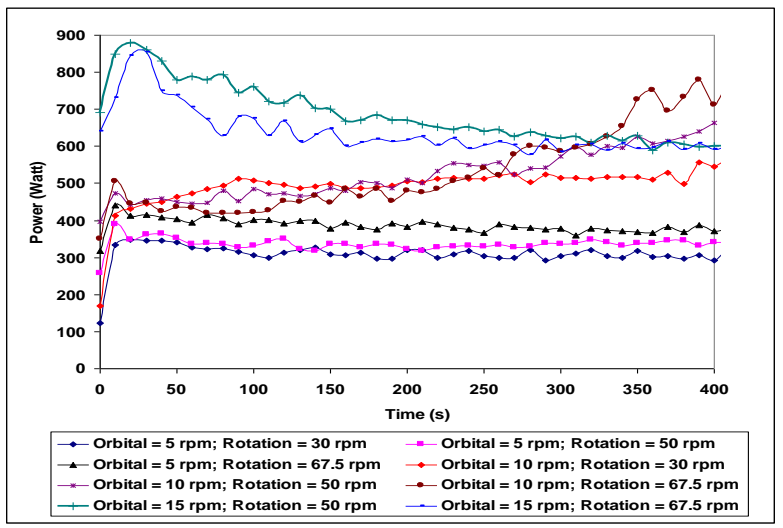

Fig. 8. Effects of orbital and rotation speeds on power consumption for particle size of $>60$ mesh

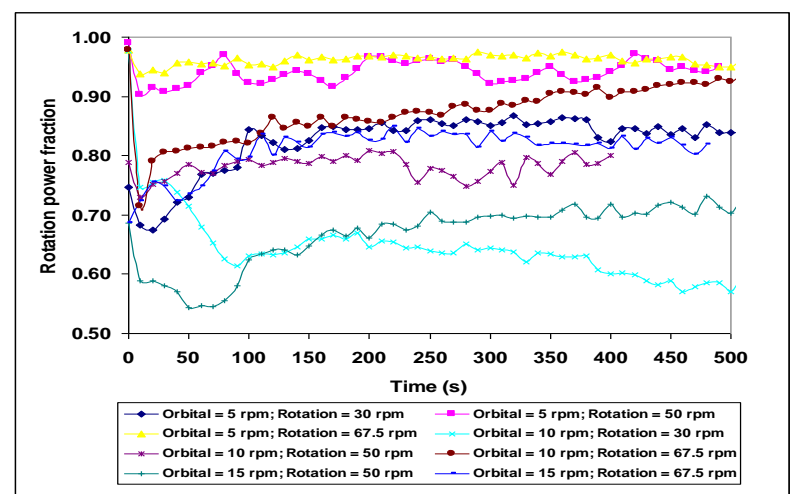

Fig. 9. Rotation power fraction for particle size of $>60$ mesh

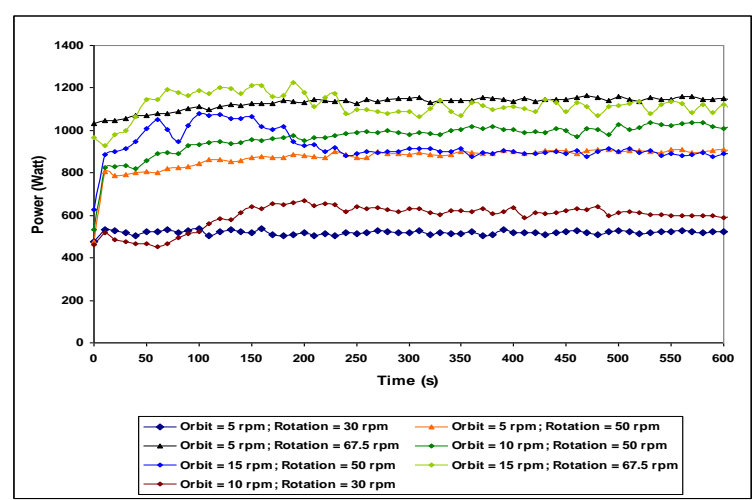

Fig. 10. Effects of orbital and rotation speeds on power consumption for particle size of $>80$ mesh 


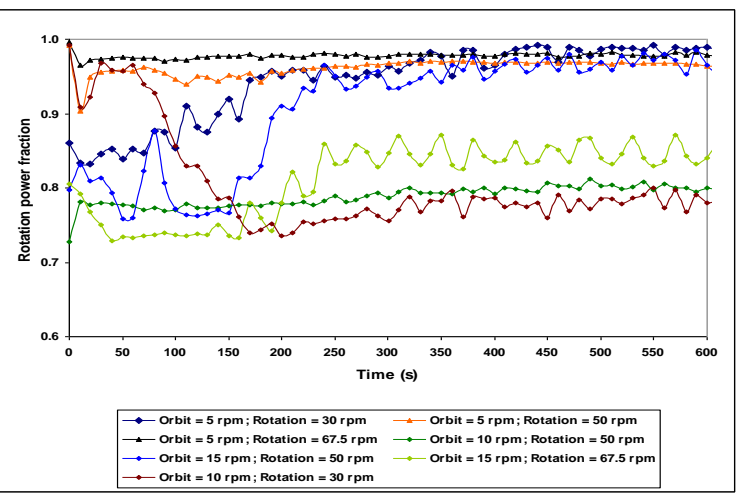

Fig. 11. Rotation power fraction for particle size of $>80$ mesh

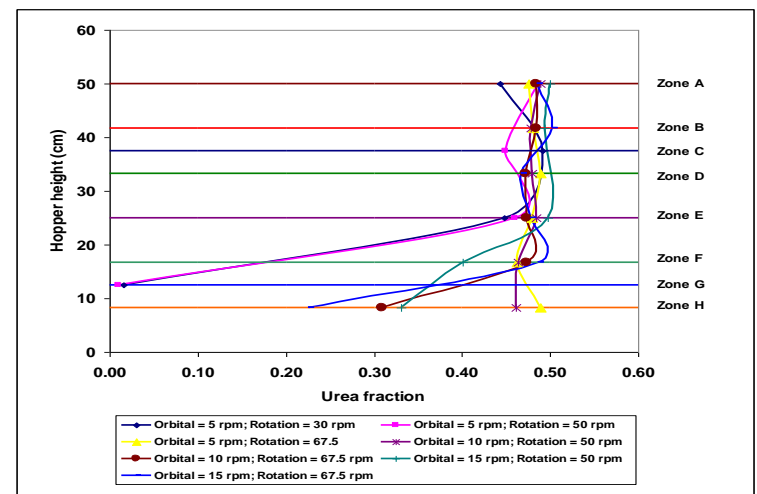

Fig. 12. Urea fraction profile for particle size> 50 mesh

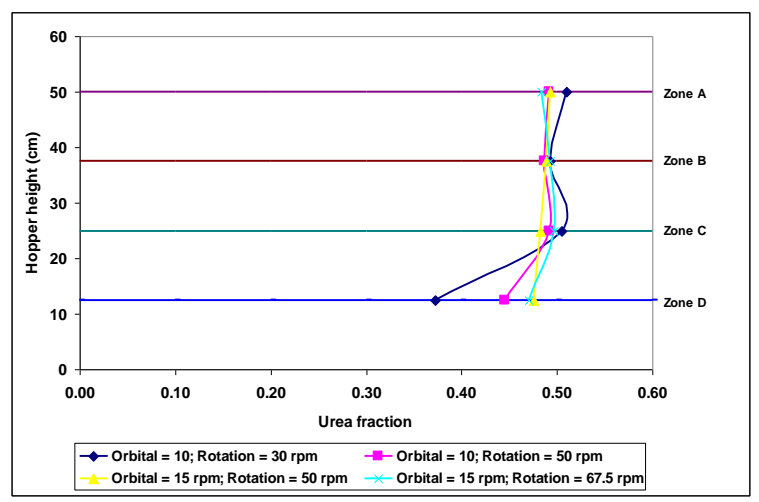

Fig. 13. Urea fraction profile for particle size $>60$ mesh

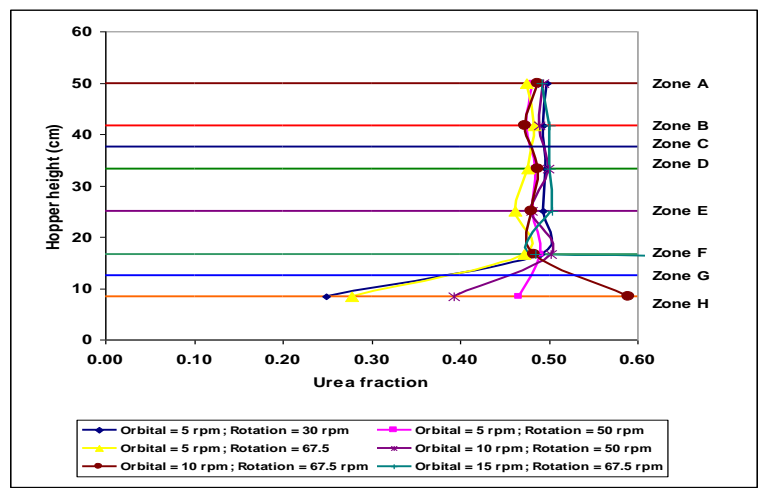

Fig. 14. Urea fraction profile for particle size $>80$ mesh 